\title{
Biofilm formation and adherence characteristics of an Elizabethkingia meningoseptica isolate from Oreochromis mossambicus
}

\author{
Anelet Jacobs ${ }^{1}$ and Hafizah Y Chenia ${ }^{2^{*}}$
}

\begin{abstract}
Background: Elizabethkingia spp. are opportunistic pathogens often found associated with intravascular devicerelated bacteraemias and ventilator-associated pneumonia. Their ability to exist as biofilm structures has been alluded to but not extensively investigated.

Methods: The ability of Elizabethkingia meningoseptica isolate $\mathrm{CH} 2 \mathrm{~B}$ from freshwater tilapia (Oreochromis mossambicus) and E. meningoseptica strain NCTC $10016^{\top}$ to adhere to abiotic surfaces was investigated using microtiter plate adherence assays following exposure to varying physico-chemical challenges. The role of cellsurface properties was investigated using hydrophobicity (bacterial adherence to hydrocarbons), autoaggregation and coaggregation assays. The role of extracellular components in adherence was determined using reversal or inhibition of coaggregation assays in conjunction with Listeria spp. isolates, while the role of cell-free supernatants, from diverse bacteria, in inducing enhanced adherence was investigated using microtitre plate assays. Biofilm architecture of isolate $\mathrm{CH} 2 \mathrm{~B}$ alone as well as in co-culture with Listeria monocytogenes was investigated using flow cells and microscopy.

Results: E. meningoseptica isolates $\mathrm{CH} 2 \mathrm{~B}$ and NCTC $10016^{\top}$ demonstrated stronger biofilm formation in nutrientrich medium compared to nutrient-poor medium at both 21 and $37^{\circ} \mathrm{C}$, respectively. Both isolates displayed a hydrophilic cell surface following the bacterial adherence to xylene assay. Varying autoaggregation and coaggregation indices were observed for the E. meningoseptica isolates. Coaggregation by isolate $\mathrm{CH} 2 \mathrm{~B}$ appeared to be strongest with foodborne pathogens like Enterococcus, Staphylococcus and Listeria spp. Partial inhibition of coaggregation was observed when isolate $\mathrm{CH} 2 \mathrm{~B}$ was treated with heat or protease exposure, suggesting the presence of heat-sensitive adhesins, although sugar treatment resulted in increased coaggregation and may be associated with a lactose-associated lectin or capsule-mediated attachment.

Conclusions: E. meningoseptica isolate $\mathrm{CH} 2 \mathrm{~B}$ and strain NCTC $10016^{\top}$ displayed a strong biofilm-forming phenotype which may play a role in its potential pathogenicity in both clinical and aquaculture environments. The ability of E. meningoseptica isolates to adhere to abiotic surfaces and form biofilm structures may result from the hydrophilic cell surface and multiple adhesins located around the cell.
\end{abstract}

Keywords: Elizabethkingia meningoseptica tilapia, biofilm, adherence, autoaggregation, coaggregation

\footnotetext{
* Correspondence: cheniah@ukzn.ac.za

${ }^{2}$ Discipline: Microbiology, University of KwaZulu-Natal, Private Bag X54001,

Durban, 4001, South Africa

Full list of author information is available at the end of the article
} 


\section{Background}

Members of the genus Elizabethkingia are aerobic, nonmotile, Gram-negative rods that display a light yellow pigmentation or may be non-pigmented [1]. The absence of gliding motility and the presence of flexirubin pigments differentiate these genera from other genera in their family Flavobacteriaceae. Only two species have been identified to date, i.e., Elizabethkingia meningoseptica and E. miricola [1].

E. meningoseptica is the most significant species for human clinical infections, although E. miricola has been associated with sepsis [2]. Elizabethkingia-related infections occur in severely immuno-compromised and postoperative patients as well as neonates [1]. E. meningoseptica has been implicated in endocarditis, cellulitis, abdominal infection, septic arthritis and eye infections in severely immuno-compromised patients [1] suffering from malignancy, end-stage hepatic and renal disease, extensive burns and acquired immune deficiency syndrome as well as community-acquired necrotizing fasciitis, pneumonia, and bacteraemia [3]. These infections constitute a major clinical concern, since together with Chryseobacterium spp., Elizabethkingia spp. isolates are constitutively resistant to multiple antibiotics $[1,4]$.

Elizabethkingia spp, isolates constitute a further threat, being able to thrive in aqueous environments and are associated with intravascular device-related bacteraemias, wound sepsis, and ventilator-associated pneumonia by virtue of their ability to contaminate and persist in fluid-containing apparatus $[2,3,5]$. E. meningoseptica has been found in the hospital environment in such sites as water supplies, saline solution used for flashing procedures, disinfectants, and medical devices, including feeding tubes and arterial catheters [6]. Outbreaks have been documented following administration of contaminated medicine, use of devices contaminated via water or more sporadic infections in immuno-compromised patients or post-trauma and -surgery patients. The bacterium has been isolated from such medical devices as the respirator, vaporizer and artificial ventilation tubing. E. meningoseptica strains isolated from slimy biofilm communities inside spouts of sink taps of a hospital have been implicated in a neonatal meningitis outbreak [7].

Elizabethkingia spp. have also been isolated from diverse ecological niches, including eutrophic lakes, soil, freshwater sources, spent nuclear fuel pools, and water condensation on the Russian space laboratory Mir [1]. E. meningoseptica have been recovered from diverse eukaryotes, including amoebae, frogs, turtles, birds, cats, dogs, and fish. The first E. meningoseptica infection in fish was diagnosed in farmed koi carp with skin lesions and hemorrhagic septicaemia. Fish-associated members of the genus Elizabethkingia may represent pathogenic or spoilage organisms or belong to the normal bacterial flora that colonize the mucus at the surface of the skin and gills and the intestine of healthy fish [1].

In the aquaculture environment, two challenges may be posed by $E$. meningoseptica, i.e., ability of these multidrug-resistant species to evade eradication following antimicrobial treatment and persistence in tanks due to biofilm community formation, leading to disease and associated economic losses; and their potential role as opportunistic human pathogens. The ability of these organisms to act as potential zoonotic pathogens, via transmission from fish and fish farm environments to immuno-compromised workers and consumers should not be underestimated [4] and necessitates investigation into their ability to adhere to surfaces and form biofilms.

Although Elizabethkingia spp. isolates have been isolated from clinical biofilm communities $[7,8]$, the factors involved in initiating biofilm formation by these nonmotile bacteria has not been elucidated. The present study investigated the ability of Elizabethkingia meningoseptica isolate $\mathrm{CH} 2 \mathrm{~B}$ from farmed freshwater tilapia and strain NCTC $10016^{\mathrm{T}}$, to adhere to polystyrene under various physico-chemical conditions using the microtiter plate assay. Hydrophobicity as well as coaggregation and autoaggregation abilities were also investigated. The role of extracellular cell components in adherence was determined using reversal and inhibition of coaggregation assays, while the effect of cell-free supernatants from diverse bacteria in inducing enhanced adherence was investigated using microtiter plate adherence assays. Biofilm architecture of $E$. meningoseptica isolate $\mathrm{CH} 2 \mathrm{~B}$ was examined using a flow cell system, as was the ability of E. meningoseptica isolate $\mathrm{CH} 2 \mathrm{~B}$ to form a mixed biofilm structure with Listeria monocytogenes.

\section{Methods}

\section{Bacterial growth conditions and identification}

Creamish-yellow pigmented isolate $\mathrm{CH} 2 \mathrm{~B}$ was cultured from diseased freshwater tilapia (Oreochromis mossambicus) from a South African aquaculture facility. Isolate $\mathrm{CH} 2 \mathrm{~B}$ was presumptively identified as E. meningoseptica using the following tests: Gram stain, colony characteristics, and flexirubin pigment production [1]; and this identification was confirmed by $16 \mathrm{~S}$ rRNA gene PCR and sequencing [9] (GenBank: EU598807).

E. meningoseptica isolate $\mathrm{CH} 2 \mathrm{~B}$ and type strain NCTC $10016^{\mathrm{T}}$ were maintained on enriched Anacker and Ordal's agar (EAOA) [10] at ambient temperature $\left(21^{\circ} \mathrm{C}\right.$ $\pm 2^{\circ} \mathrm{C}$ ). For long-term storage, cultures were placed in $20 \%$ glycerol and enriched Anacker and Ordal's broth $(\mathrm{EAOB})$ and stored at $-80^{\circ} \mathrm{C}$. 


\section{Biofilm formation and quantification}

E. meningoseptica isolates $\mathrm{CH} 2 \mathrm{~B}$ and NCTC $10016^{\mathrm{T}}$ were cultured overnight in $\mathrm{EAOB}$ at room temperature $\left(21^{\circ} \mathrm{C} \pm 2^{\circ} \mathrm{C}\right)$ and centrifuged for $2 \mathrm{~min}$ at $12000 \mathrm{rpm}$. Cell pellets were washed and re-suspended in phosphate-buffered saline (PBS, $\mathrm{pH} 7.2$ ) to a turbidity equivalent to a $0.5 \mathrm{M}$ McFarland standard [11]. In order to determine bacterial microtitre plate adherence, wells of sterile 96-well U-bottomed polystyrene microtiter plates (Deltalabs S.L, Barcelona, Spain) were each filled with $90 \mu \mathrm{l} \mathrm{EAOB/tryptic} \mathrm{soy} \mathrm{broth} \mathrm{(TSB;} \mathrm{Merck} \mathrm{Chemi-}$ cals, Gauteng, RSA) and inoculated with $10 \mu \mathrm{l}$ of standardized cell suspensions, in triplicate [12]. Negative control wells containing only broth or PBS were included in each assay while a Vibrio mimicus isolate (VIB1; isolated from cultured trout) was used as a positive control. Plates were placed on a $\mathrm{C} 1$ platform shaker (New Brunswick Scientific, Edison, NJ, USA) and/or the benchtop to simulate dynamic and static conditions, respectively, and incubated aerobically at room temperature $\left(21^{\circ} \mathrm{C} \pm 2^{\circ} \mathrm{C}\right)$ and/or $37^{\circ} \mathrm{C}$ for $24 \mathrm{~h}$, in either nutrient-poor $\mathrm{EAOB} /$ nutrient-rich TSB media. An optical density (OD) reading of each well was obtained at 595 $\mathrm{nm}$ using an automated microtiter-plate reader (Microplate Reader model 680, BioRad Laboratories Inc., Hercules, California). Tests were done in triplicate on three separate occasions and the results averaged [12].

Biofilm formation was classified as non-adherent, weakly-, moderately- or strongly-adherent. The cut-off $\mathrm{OD}\left(\mathrm{OD}_{\mathrm{c}}\right)$ for the microtiter plate test was defined as three standard deviations above the mean OD of the negative control. Isolates were classified as follows: $\mathrm{ODOD}_{\mathrm{C}}=$ non-adherent, $\mathrm{OD}_{\mathrm{C}}<\mathrm{OD}\left(2 \times \mathrm{OD}_{\mathrm{C}}\right)=$ weakly adherent; $\left(2 \times \mathrm{OD}_{\mathrm{C}}\right)<\mathrm{OD} \leq\left(4 \times \mathrm{OD}_{\mathrm{C}}\right)=$ moderately adherent and $\left(4 \times \mathrm{OD}_{\mathrm{C}}\right)<\mathrm{OD}=$ strongly adherent [12]. Statistical significance of differences $(p<0.05)$ due to altered variables (temperature, medium, agitation) in the microtiter adherence assays were determined using one way repeated measures analysis of variance (ANOVA; SigmaStat, V3.5, Systat Software, Inc., USA).

\section{Bacterial adherence to hydrocarbon assay}

Surface hydrophobicity was assessed using the bacterial adherence to hydrocarbons (BATH) assay, with xylene (BDH, VWR International, Leicestershire, UK) as the hydrocarbon of choice [11]. E. meningoseptica isolates $\mathrm{CH} 2 \mathrm{~B}$ and NCTC $10016^{\mathrm{T}}$ grown in EAOB at room temperature $\left(21^{\circ} \mathrm{C} \pm 2^{\circ} \mathrm{C}\right)$ were harvested during the exponential growth phase (18 h old cultures), washed three times and resuspended in sterile $0.1 \mathrm{M}$ phosphate buffer $(\mathrm{pH} 7)$ to an OD of 0.8 at a wavelength of $550 \mathrm{~nm}\left(\mathrm{~A}_{0}\right.$ of $\left.10^{8} \mathrm{CFU} / \mathrm{ml}\right)$. Samples $(3 \mathrm{ml})$ of the bacterial suspension were placed in glass tubes with $400 \mu$ l of xylene, equilibrated in a water bath at $25^{\circ} \mathrm{C}$ for $10 \mathrm{~min}$ and vortexed [11,13]. After a $15 \mathrm{~min}$ phase separation, the lower aqueous phase was removed and its $\mathrm{OD}_{550}$ determined $\left(A_{1}\right)$. Strains were considered strongly hydrophobic when values were $>50 \%$, moderately hydrophobic when values were in the range of $20-50 \%$, and hydrophilic when values were $<20 \%$ [14]. Each value represents the mean of experiments done in triplicate and on two separate occasions. PBS was used as a negative control and $V$. mimicus isolate VIB1 was used as a control [11].

For the modified salting aggregation test (SAT) assay, overnight $\mathrm{EAOB}$ cultures grown at room temperature $\left(21^{\circ} \mathrm{C} \pm 2^{\circ} \mathrm{C}\right)$ were harvested, washed twice and resuspended in PBS (pH 7.2). E. meningoseptica isolate $\mathrm{CH} 2 \mathrm{~B}$ was 'salted out' (aggregated) by combining $25 \mu$ l volumes, containing $2 \times 10^{9}$ bacteria, with $25 \mu \mathrm{l}$ volumes of a series of methylene blue-containing ammonium sulphate $\left[\left(\mathrm{NH}_{4}\right)_{2} \mathrm{SO}_{4}\right]$ concentrations $(0.2,0.5,1,1.5,2,2.5,3$, and $4 \mathrm{M})$ on microscope slides [11]. The lowest final concentration of $\left(\mathrm{NH}_{4}\right)_{2} \mathrm{SO}_{4}$ causing aggregation was recorded as the SAT value and classified as follows: $<0.1 \mathrm{M}=$ highly hydrophobic, $0.1 \mathrm{M}-1.0 \mathrm{M}=$ hydrophobic and $>1.0 \mathrm{M}=$ hydrophilic [15]. Experiments were done in triplicate on two separate occasions and respective $\left(\mathrm{NH}_{4}\right)$ ${ }_{2} \mathrm{SO}_{4}$ concentrations were used as negative controls.

\section{Autoaggregation and coaggregation assays}

For the autoaggregation assay, E. meningoseptica isolates $\mathrm{CH} 2 \mathrm{~B}$ and NCTC $10016^{\mathrm{T}}$ were grown in $20 \mathrm{ml} \mathrm{EAOB}$ at room temperature $\left(21^{\circ} \mathrm{C} \pm 2^{\circ} \mathrm{C}\right)$, harvested after $36 \mathrm{~h}$, washed and re-suspended in sterile distilled $\mathrm{H}_{2} \mathrm{O}$ to an OD of 0.3 at a wavelength of $660 \mathrm{~nm}$. The percentage of autoaggregation was measured by transferring a $1 \mathrm{ml}$ sample of bacterial suspension to a sterile plastic $2 \mathrm{ml}$ cuvette and measuring the OD after 60 min using a DU 640 spectrophotometer (Beckman Coulter) at a wavelength of $660 \mathrm{~nm}$ [16]. The degree of autoaggregation was determined as the percent decrease of optical density after 60 min using the equation:

$$
\% \text { Autoaggregation }=\frac{O D_{o}-O D_{60}}{O D_{o}} \times 100
$$

$\mathrm{OD}_{0}$ refers to the initial $\mathrm{OD}$ of the organism measured. Sixty min after $\mathrm{OD}_{0}$ was obtained, the cell suspension was centrifuged at $2000 \mathrm{rpm}$ for $2 \mathrm{~min}$. The $\mathrm{OD}$ of the supernatant was measured $\left(\mathrm{OD}_{60}\right)$. Experiments were carried out in triplicate on two separate occasions [16].

E. meningoseptica isolates $\mathrm{CH} 2 \mathrm{~B}$ and NCTC $10016^{\mathrm{T}}$ were examined for their ability to coaggregate with each other as well as with the following bacterial partner strains: Aeromonas hydrophila, A. sobria, A. salmonicida, A. media, Acinetobacter spp., Enterococcus faecalis ATCC 
29212, Escherichia coli ATCC 25922, Flavobacterium johnsoniae-like spp. isolates YO12, YO19, YO51, YO60, YO64, Listeria monocytogenes NCTC 4885, L. innocua LMG 13568, Micrococcus luteus, Pseudomonas aeruginosa, Salmonella enterica serovar Arizonae and Staphylococcus aureus ATCC 25923 [11].

For coaggregation assays, bacteria were grown in 20 $\mathrm{ml}$ EAOB or TSB, harvested after $36 \mathrm{~h}$, washed and resuspended in sterile distilled $\mathrm{H}_{2} \mathrm{O}$ to an OD of 0.3 at a wavelength of $660 \mathrm{~nm}$. The degree of coaggregation was determined by OD readings of paired isolate suspensions $(500 \mu \mathrm{l}$ of each isolate). The cell mixture was centrifuged at $2000 \mathrm{rpm}$ for $2 \mathrm{~min}$ and the OD of the supernatant $(600 \mu \mathrm{l})$ was measured at a wavelength of $660 \mathrm{~nm}$ [16]. The quantitative coaggregation rate of paired isolates was calculated using the equation:

$$
\% \text { Coaggregation }=\frac{O D_{T o t}-O D_{S}}{O D_{T o t}} \times 100
$$

where $O D_{\text {Tot }}$ value refers to the initial $O D$, taken immediately after the relevant strains were paired; and $\mathrm{OD}_{\mathrm{S}}$ refers to the OD of the supernatant, after the mixture was centrifuged after $60 \mathrm{~min}$ [16]. Experiments were carried out in triplicate on two separate occasions. Differences in coaggregation between $E$. meningoseptica $\mathrm{CH} 2 \mathrm{~B}$ and E. meningoseptica NCTC $10016^{\mathrm{T}}$ were determined using one way repeated measures analysis of variance (ANOVA; SigmaStat V3.5). Differences were considered significant if $p<0.05$.

\section{Reversal and inhibition of coaggregation}

The effect of simple sugars, heat and protease treatment on isolate CH2B's ability to coaggregate with $L$. innocua LMG 13568 and L. monocytogenes NCTC 4885 was investigated.

The ability of simple sugars to reverse E. meningoseptica isolate $\mathrm{CH} 2 \mathrm{~B}$ coaggregation with Listeria spp. involved filter-sterilized solutions of lactose and galactose, respectively, being added to one of the coaggregating partners at final concentrations of $50 \mathrm{mM}$ [17]. Mixtures were vortexed and tested for coaggregation using the coaggregation assay described above.

The ability of heat treatment to inhibit E. meningoseptica isolate $\mathrm{CH} 2 \mathrm{~B}$ coaggregation with Listeria spp. was conducted using the method of Kolenbrander et al. [18]. Cells were harvested from $\mathrm{O} / \mathrm{N}$ EAOB/TSB cultures, washed three times and resuspended in de-ionized water. One of the coaggregating partners was then heated at $80^{\circ} \mathrm{C}$ for $30 \mathrm{~min}$ in a waterbath. Following heat treatment, the OD of each bacterial suspension was adjusted to 0.3 at a wavelength of $660 \mathrm{~nm}$. Heat-treated and untreated cells were combined in reciprocal pairs and their capacity to coaggregate was assessed.
Protease sensitivity of the polymers mediating coaggregation of isolate $\mathrm{CH} 2 \mathrm{~B}$ with Listeria spp. isolates was tested using a method described by Rickard et al. [19]. Cells were harvested from $\mathrm{O} / \mathrm{N}$ EAOB/TSB cultures and resuspended in de-ionized water to an OD of 0.3 at a wavelength of $660 \mathrm{~nm}$. Proteinase $\mathrm{K}$ was added to the standardized cell suspensions to a final concentration of $2 \mathrm{mg} / \mathrm{ml}$. Incubation at $37^{\circ} \mathrm{C}$ for $2 \mathrm{~h}$ was followed by centrifugation and washing of the pelleted cells three times in de-ionized water. Cells were resuspended and the OD adjusted to 0.3 at $660 \mathrm{~nm}$. Protease-treated and untreated cells were combined and their capacity to coaggregate determined.

Differences in coaggregation between untreated E. meningoseptica $\mathrm{CH} 2 \mathrm{~B}$ and treated bacteria (E. meningoseptica CH2B, L. innocua, and L. monocytogenes) were determined by paired t-tests (SigmaStat V3.5). Differences were considered significant if $p<0.05$.

\section{Induction of adherence}

The standard microtiter plate adherence test [12] was modified to determine the ability of extracellular secretions of various aquaculture, food and/or human pathogens (Aeromonas hydrophila, A. salmonicida, A. sobria, Chryseobacterium spp. isolates $\mathrm{CH} 8, \mathrm{CH} 15, \mathrm{CH} 23$, $\mathrm{CH} 25$ and $\mathrm{CH} 34$, E. meningoseptica $\mathrm{CH} 2 \mathrm{~B}$, E. coli, Edwardsiella tarda, F. johnsoniae-like isolate YO59, L. innocua, L. monocytogenes, Myroides odoratus MY1, $P$. aeruginosa, S. enterica serovar Arizonae, and $V$. mimicus VIB1) to induce enhanced adherence of E. meningoseptica $\mathrm{CH} 2 \mathrm{~B}$.

Three-day old cultures of each of the above organisms were centrifuged at $2000 \mathrm{rpm}$ for $10 \mathrm{~min}$ and supernatants were filter-sterilised using $0.2 \mu \mathrm{m}$ filters, in order to obtain cell-free spent medium. E. meningoseptica $\mathrm{CH} 2 \mathrm{~B}$ cell pellets were washed and re-suspended in phosphate-buffered saline (PBS, pH 7.2) to a turbidity equivalent to a $0.5 \mathrm{M}$ McFarland standard [11]. Ten $\mu$ l of the standardized suspension was added to microtiter wells containing $100 \mu \mathrm{l}$ TSB and $90 \mu \mathrm{l}$ of the filtered supernatant. Controls included standardised isolate $\mathrm{CH} 2 \mathrm{~B}$ cell suspension added to TSB and respective filtered supernatants in TSB without isolate $\mathrm{CH} 2 \mathrm{~B}$, in order to determine a change in adherence abilities and ensure that the change in adherence was due to induction, respectively. Microtiter plates were incubated at room temperature $\left(21^{\circ} \mathrm{C} \pm 2^{\circ} \mathrm{C}\right)$ for $48 \mathrm{~h}$. An optical density (OD) reading of each well was obtained at $595 \mathrm{~nm}$ using an automated microtiterplate reader (Microplate Reader model 680, BioRad Laboratories Inc., Hercules, California). Tests were done in triplicate on three separate occasions and the results averaged [12]. 


\section{Characterization of biofilm formation using flow cell systems}

Biofilm formation by $E$. menigoseptica isolate $\mathrm{CH} 2 \mathrm{~B}$ was investigated using continuous culture once-through eight channel flow-cell system, while the mixed-species biofilm flow cell study involved $L$. monocytogenes strain NCTC 4885 together with isolate $\mathrm{CH} 2 \mathrm{~B}$. The eightchannel perspex flow cell (channel size $30 \times 4.5 \times 3$ $\mathrm{mm}$ ), the glass cover-slip covering (no. 1 thickness, 75 $\mathrm{mm}$ by $50 \mathrm{~mm})$, and attached silicone tubing $(1 \times 1.6$ $\mathrm{mm} \times 3 \mathrm{~mm} \times 5 \mathrm{~m}$ tubing; The Silicone Tube, RSA) was assembled as described previously [11]. Silicone tubing was connected to a reservoir containing 21 of $\mathrm{EAOB} / \mathrm{TSB}$ and the flow cell was filled with $\mathrm{EAOB} / \mathrm{TSB}$, with a flow rate of $0.25 \mathrm{ml} / \mathrm{min}$ being maintained using a multi-channel peristaltic pump (Model 205S, WatsonMarlow, UK) located upstream of the flow cell. A one $\mathrm{ml}$ volume of $\mathrm{EAOB}$ overnight cultures of isolate $\mathrm{CH} 2 \mathrm{~B}$ was inoculated into each channel, below the clamps sealing silicone tubes upstream of each channel, using sterile syringes. One $\mathrm{ml}$ mixed pure culture inoculations, consisted of $0.5 \mathrm{ml}$ combinations of E. meningoseptica isolate CH2B and L. monocytogenes NCTC 4885. Stagnant conditions were maintained for the first hour to allow attachment, prior to inoculated channels being exposed to flowing EAOB/TSB at a constant flow rate of $0.25 \mathrm{ml} / \mathrm{min}$. Flow cell systems were kept at room temperature $\left(21^{\circ} \mathrm{C} \pm 2\right)$ throughout the experiments. Each flow cell channel was investigated by transmitted light using a Nikon Eclipse E400 (Nikon, Japan) microscope at 600-fold magnification and after $24 \mathrm{~h}$ and $48 \mathrm{~h}$, respectively, to visualize bacterial attachment to a glass surface and biofilm development. Images were documented with a CHU high-performance charge-coupled camera device (model 4912-5010/000).

\section{Results}

\section{Biofilm-forming ability of $E$. meningoseptica}

E. meningoseptica isolates CH2B and NCTC $10016^{\mathrm{T}}$, as well as $V$. mimicus VIB1 were screened for their adherence to polystyrene microtitre plate wells following $24 \mathrm{~h}$ incubation at room temperature $\left(21^{\circ} \mathrm{C} \pm 2^{\circ} \mathrm{C}\right)$ or $37^{\circ} \mathrm{C}$, under static or dynamic conditions in nutrient-rich (TSB) or nutrient-poor (EAOB) media (Table 1).

Isolate $\mathrm{CH} 2 \mathrm{~B}$ displayed moderate adherence in $\mathrm{EAOB}$ at both room temperature and $37^{\circ} \mathrm{C}$, respectively, and became strongly adherent when exposed to TSB (Table 1). E. meningoseptica NCTC $10016^{\mathrm{T}}$ was moderately adherently at room temperature and strongly adherent at $37^{\circ} \mathrm{C}$ in TSB, but weakly adherent in EAOB. In contrast, $V$. mimicus displayed strongest adherence in $\mathrm{EAOB}$ at room temperature. An increase in temperature to $37^{\circ} \mathrm{C}$ or alteration of the medium to TSB resulted in weak to moderate adherence for $V$. mimicus (Table 1). Given the small sample number, none of the physicochemical parameter combinations resulted in statistically significant adherence.

\section{Bacterial hydrophobicity}

Both E. meningoseptica isolate $\mathrm{CH} 2 \mathrm{~B}$ and $E$. meningoseptica NCTC $10016^{\mathrm{T}}$ appeared to be strongly hydrophilic with BATH indices of $0.77 \%$ and $0.36 \%$, respectively. Isolate $\mathrm{CH} 2 \mathrm{~B}$ was 'salted out' with a $4 \mathrm{M}\left(\mathrm{NH}_{4}\right)_{2} \mathrm{SO}_{4}$ concentration, confirming its hydrophilicity.

Table 1 Biofilm formation by Elizabethkingia meningoseptica isolates CH2B and NCTC $10016^{\top}$ following incubation at room temperature $\left(\sim 21^{\circ} \mathrm{C}\right)$ or $37^{\circ} \mathrm{C}$, under static or dynamic conditions in nutrient-poor (EAOB) media or nutrient-rich (TSB), respectively

\begin{tabular}{|c|c|c|c|c|c|c|}
\hline \multirow[t]{3}{*}{ Parameters } & \multicolumn{6}{|c|}{ Biofilm formation $\left(\mathrm{OD}_{595 \mathrm{~nm}} \pm \mathrm{SD}\right)^{\mathrm{a}}$} \\
\hline & \multicolumn{4}{|c|}{ Elizabethkingia meningoseptica } & \multicolumn{2}{|c|}{ Vibrio mimicus } \\
\hline & $\mathrm{CH} 2 \mathrm{~B}$ & $\mathrm{BF}^{\mathrm{b}}$ & NCTC $10016^{\top}$ & $\mathrm{BF}^{\mathrm{b}}$ & VIB1 & $\mathrm{BF}^{\mathrm{b}}$ \\
\hline $21^{\circ} \mathrm{C}$ EAOB dynamic & $0.23 \pm 0.02$ & M & $0.07 \pm 0.01$ & $\mathrm{~N}$ & $1.34 \pm 0.28$ & $S$ \\
\hline $21^{\circ} \mathrm{C}$ EAOB static & $0.31 \pm 0.13$ & M & $0.16 \pm 0.01$ & W & $1.01 \pm 0.18$ & $\mathrm{~S}$ \\
\hline $21^{\circ} \mathrm{C}$ TSB dynamic & $0.44 \pm 0.14$ & $\mathrm{~S}$ & $0.25 \pm 0.01$ & M & $0.11 \pm 0.00$ & W \\
\hline $21^{\circ} \mathrm{C}$ TSB static & $0.56 \pm 0.06$ & $S$ & $0.26 \pm 0.02$ & M & $0.14 \pm 0.07$ & W \\
\hline $37^{\circ} \mathrm{C}$ EAOB dynamic & $0.38 \pm 0.19$ & M & $0.11 \pm 0.07$ & W & $0.30 \pm 0.09$ & W \\
\hline $37^{\circ} \mathrm{C}$ EAOB static & $0.46 \pm 0.35$ & M & $0.27 \pm 0.06$ & M & $0.37 \pm 0.15$ & W \\
\hline $37^{\circ} \mathrm{C}$ TSB dynamic & $0.84 \pm 0.17$ & S & $0.36 \pm 0.02$ & S & $0.34 \pm 0.39$ & M \\
\hline $37^{\circ} \mathrm{C}$ TSB static & $0.90 \pm 0.07$ & S & $0.42 \pm 0.05$ & S & $0.27 \pm 0.34$ & M \\
\hline
\end{tabular}

${ }^{a}$ Biofilm formation assay data is the mean of three independent experiments carried out in triplicate \pm standard deviation following growth in minimal (EAOB) or rich (TSB) media at 21 or $37^{\circ} \mathrm{C}$ under dynamic or static conditions, respectively.

${ }^{\mathrm{b}}$ Biofilm formation (BF) was classified as non-adherent (N), weakly (W)-, moderately (M)- or strongly (S)-adherent using previously described criteria [12]. 


\section{Autoaggregation and coaggregation indices}

Isolate $\mathrm{CH} 2 \mathrm{~B}$ displayed an autoaggregation index of $37.4 \%$ (Table 2), while that of the type strain E. meningoseptica NCTC $10016^{\mathrm{T}}$ was $33.1 \%$. Coaggregation occurred to varying degrees between all of the 18 partner strains and E. meningoseptica isolates $\mathrm{CH} 2 \mathrm{~B}$ or NCTC $10016^{\mathrm{T}}$ (Table 2), respectively. Isolate CH2B displayed coaggregation indices ranging from $2.5 \%$ with $E$. meningoseptica NCTC $10016^{\mathrm{T}}$ to $82.2 \%$ with $S$. aureus

Table 2 Range of coaggregation indices obtained when partnering Elizabethkingia meningoseptica isolates $\mathrm{CH} 2 \mathrm{~B}$ and NCTC $10016^{\mathrm{T}}$ with 19 diverse bacterial partner isolates

\begin{tabular}{|c|c|c|}
\hline $\begin{array}{l}\text { Coaggregation partner } \\
\text { strains }^{\mathrm{a}}\end{array}$ & $\begin{array}{c}\text { Coaggregation } \\
\text { indices }(\%)^{\mathrm{b}} \text { with } \\
\mathrm{CH} 2 \mathrm{~B}\end{array}$ & $\begin{array}{l}\text { Coaggregation } \\
\text { indices }(\%)^{\mathbf{b}} \text { with } \\
\text { NCTC } 10016^{\top}\end{array}$ \\
\hline $\begin{array}{c}\text { Elizabethkingia } \\
\text { meningoseptica } \mathrm{CH} 2 \mathrm{~B} \\
(37.4 \%)\end{array}$ & 37.4 & 2.5 \\
\hline $\begin{array}{c}\text { Elizabethkingia } \\
\text { meningoseptica NCTC } \\
10016^{\top}(33.12 \%)\end{array}$ & 2.5 & 33.1 \\
\hline $\begin{array}{c}\text { Acinetobacter spp. } \\
(25.4 \%)\end{array}$ & 32.7 & 37.9 \\
\hline $\begin{array}{c}\text { Aeromonas salmonicida } \\
(41.8 \%)\end{array}$ & 31.6 & 45.0 \\
\hline $\begin{array}{c}\text { Aeromonas hydrophila } \\
(28.3 \%)\end{array}$ & 18.1 & 39.6 \\
\hline $\begin{array}{c}\text { Aeromonas media } \\
(20.3 \%)\end{array}$ & 38.03 & $N T^{c}$ \\
\hline Aeromonas sobria (27.5\%) & 27.5 & 10.6 \\
\hline $\begin{array}{l}\text { Enterococcus faecalis } \\
\text { ATCC } 29212(45.0 \%)\end{array}$ & 44.3 & 6.9 \\
\hline $\begin{array}{c}\text { Escherichia coli ATCC } \\
25922(20.8 \%)\end{array}$ & 39.5 & 32.3 \\
\hline \multicolumn{3}{|l|}{$\begin{array}{c}\text { Flavobacterium } \\
\text { johnsoniae-like isolates }\end{array}$} \\
\hline Y012 (33.9\%) & 36.6 & 42.5 \\
\hline YO19 (16.1\%) & 28.9 & 13.0 \\
\hline YO51 (13.9\%) & 25.2 & 24.0 \\
\hline YO60 (27.5\%) & 18.0 & 38.2 \\
\hline YO64 (20.1\%) & 16.7 & 56.5 \\
\hline $\begin{array}{l}\text { Listeria innocua LMG } \\
13568(56.2 \%)\end{array}$ & 77.4 & 47.7 \\
\hline $\begin{array}{l}\text { Listeria monocytogenes } \\
\text { NCTC } 4885 \text { (28.9\%) }\end{array}$ & 70.4 & NT \\
\hline Micrococcus spp. (51.1\%) & 37.2 & 75.1 \\
\hline $\begin{array}{c}\text { Pseudomonas aeruginosa } \\
(24.3 \%)\end{array}$ & 44.1 & 40.5 \\
\hline $\begin{array}{l}\text { Salmonella enterica } \\
\text { serovar Arizonae (71.9\%) }\end{array}$ & 46.0 & 65.1 \\
\hline $\begin{array}{l}\text { Staphylococcus aureus } \\
\text { ATCC } 25923(76.1 \%)\end{array}$ & 82.2 & 68.9 \\
\hline
\end{tabular}

${ }^{a}$ For partner strains, autoaggregation indices were determined using assay described by Malik et al. [16] and are indicated within ().

${ }^{\mathrm{b}}$ Coaggregation indices represent the means of two independent replicate experiments as described by Malik et al. [16] and Basson et al. [11].

${ }^{c}$ NT refers to not tested.
ATCC 25923. Isolate $\mathrm{CH} 2 \mathrm{~B}$ had coaggregation indices $>40 \%$ with $31.8 \%$ of the partner strains (Table 2 ). E. meningoseptica NCTC $10016^{\mathrm{T}}$ displayed coaggregation indices ranging from $2.5 \%$ with $E$. meningoseptica $\mathrm{CH} 2 \mathrm{~B}$ to $75.1 \%$ with a Micrococcus spp. isolate. Strain NCTC $10016^{\mathrm{T}}$ had coaggregation indices $>40 \%$ with $42.1 \%$ of the partner strains (Table 2). Although, differences were observed in the coaggregation indices profiles of $E$. meningoseptica $\mathrm{CH} 2 \mathrm{~B}$ and E. meningoseptica NCTC $10016^{\mathrm{T}}$, these were not statistically significant.

\section{Reversal and inhibition of autoaggregation and coaggregation}

Since coaggregation indices of $70.4 \%$ and $77.4 \%$ were obtained between isolate $\mathrm{CH} 2 \mathrm{~B}$ and L. monocytogenes NCTC 4885 and L. innocua LMG 13568 (Table 2), respectively, they were selected for the reversal and inhibition of coaggregation assays following sugars, heat or proteinase $\mathrm{K}$ treatments.

Sugar reversal experiments with lactose or galactose of either partner increased both the autoaggregation and coaggregation indices (Table 3 ). Lactose treatment resulted in greater coaggregation of isolate $\mathrm{CH} 2 \mathrm{~B}$ with both treated and untreated L. innocua LMG 13568 compared with $L$. monocytogenes NCTC 4885 , while this was reversed following galactose treatment, with greater coaggregation being observed with treated and untreated L. monocytogenes NCTC 4885.

Heat treatment of isolate $\mathrm{CH} 2 \mathrm{~B}$ resulted in a decrease in autoaggregation (Table 3) and coaggregation, respectively. A greater decrease in coaggregation was observed with untreated $L$. monocytogenes NCTC 4885 than with untreated L. innocua LMG 13568. However, increased coaggregation was observed when the Listeria spp. partner strains were treated with heat (Table 3).

A similar trend was observed with proteinase $\mathrm{K}$ treatment of isolate $\mathrm{CH} 2 \mathrm{~B}$, i.e., decreased autoaggregation of $\mathrm{CH} 2 \mathrm{~B}$ as well as coaggregation with the untreated partner strains. Proteinase K treatment of Listeria spp. isolates resulted in increased coaggregation between $L$. monocytogenes NCTC 4885 and isolate CH2B (Table 3). A greater reduction in the coaggregation indices were observed when heat- or protease-treated isolate $\mathrm{CH} 2 \mathrm{~B}$ cells were partnered with L. monocytogenes NCTC 4885 than with L. innocua LMG 13568.

\section{Cell-free supernatant induction of adherence}

Following exposure to cell-free supernatants from the three Aeromonas spp. isolates, Chryseobacterium spp. isolates $\mathrm{CH} 8$ and $\mathrm{CH} 25$ and $V$. mimicus, isolate $\mathrm{CH}_{2} \mathrm{~B}$ 's adherence decreased 0.48 - 1-fold (Figure 1). Increased adherence, ranging from 1.3 - 3.58-fold was observed with the remaining cell-free supernatants (Figure 1). Cell-free supernatants from Chryseobacterium spp. 
Table 3 Reversal and inhibition of autoaggregation and coaggregation following sugar, heat or proteinase $K$ treatment of Elizabethkingia meningoseptica CH2B, $L$. innocua LMG 13568, and/or L. monocytogenes NCTC 4885

\begin{tabular}{|c|c|c|c|}
\hline \multirow[t]{3}{*}{ Treatment } & \multicolumn{3}{|c|}{${\text { Coaggregation indices }(\%)^{a}}^{a}$} \\
\hline & \multirow[b]{2}{*}{$\mathrm{CH} 2 \mathrm{~B}$} & \multicolumn{2}{|c|}{ Untreated } \\
\hline & & $\begin{array}{c}L . \\
\text { innocua }\end{array}$ & $\begin{array}{c}\text { L. } \\
\text { monocytogenes }\end{array}$ \\
\hline \multicolumn{4}{|l|}{ Untreated } \\
\hline $\mathrm{CH} 2 \mathrm{~B}$ & 37.4 & 77.3 & 70.4 \\
\hline \multicolumn{4}{|l|}{$50 \mathrm{mM}$ Lactose reversal $(p=0.03)$} \\
\hline $\mathrm{CH} 2 \mathrm{~B}$ & 68.7 & 96.0 & 89.6 \\
\hline L. innocua LMG 13568 & 94.5 & - & - \\
\hline L. monocytogenes NCTC 4885 & 87.8 & - & - \\
\hline \multicolumn{4}{|l|}{$\begin{array}{c}50 \mathrm{mM} \text { Galactose reversal } \\
\qquad(p=0.07)\end{array}$} \\
\hline $\mathrm{CH} 2 \mathrm{~B}$ & 56.4 & 86.2 & 95.7 \\
\hline L. innocua LMG 13568 & 85.0 & - & - \\
\hline L. monocytogenes NCTC 4885 & 95.8 & - & - \\
\hline \multicolumn{4}{|l|}{$\begin{array}{l}\text { Heat inhibition }\left(80^{\circ} \mathrm{C} \text { for } 30 \mathrm{~min}\right) \\
\qquad(p=0.08)\end{array}$} \\
\hline $\mathrm{CH} 2 \mathrm{~B}$ & 20.9 & 33.5 & 12.9 \\
\hline L. innocua LMG 13568 & 93.8 & - & - \\
\hline L. monocytogenes NCTC 4885 & 97.7 & - & - \\
\hline \multicolumn{4}{|l|}{$\begin{array}{l}\text { Proteinase } \mathbf{K} \text { inhibition }(\mathbf{2} \mathbf{~} \mathbf{g} / \mathbf{m l}) \\
\qquad(p=0.13)\end{array}$} \\
\hline $\mathrm{CH} 2 \mathrm{~B}$ & 25.8 & 38.2 & 5.8 \\
\hline L. innocua LMG 13568 & 80.4 & - & - \\
\hline L. monocytogenes NCTC 4885 & 94.6 & - & - \\
\hline
\end{tabular}

${ }^{a}$ Coaggregation indices represent the means of two independent replicate experiments as described by Malik et al. [16] and Basson et al. [11].

isolates $\mathrm{CH} 15$ and $\mathrm{CH} 34, P$. aeruginosa, L. innocua, and L. monocytogenes increased adhesion 2 - 4-fold. A 1.5fold increase in adherence was observed following exposure of isolate $\mathrm{CH} 2 \mathrm{~B}$ to its own cell-free supernatant (Figure 1).

\section{Visualisation of biofilm formation using flow cells and microscopy}

Adherence of isolate $\mathrm{CH} 2 \mathrm{~B}$ to glass coverslips was investigated by light microscopy, starting from the surface of the glass slide and scanning several planes interspersed by short distances in order to visualize biofilm architecture and microbial behavior throughout the depth of the individual flow chambers. By $24 \mathrm{~h}$ in nutrient-poor (EAOB) medium, isolate $\mathrm{CH} 2 \mathrm{~B}$ displayed initial widespread attachment to the glass coverslips and microcolonies were observed. After $48 \mathrm{~h}$, majority of the cells were attached at a polar end (Figure 2), and conestructures were observed with chains of cells reaching into the flowing medium. In nutrient-rich (TSB) medium flow cells, cells were attached along their length in microcolonies interspersed with polarly-attached cells (Figure 3a). Microcolonies merged by $48 \mathrm{~h}$ to form a

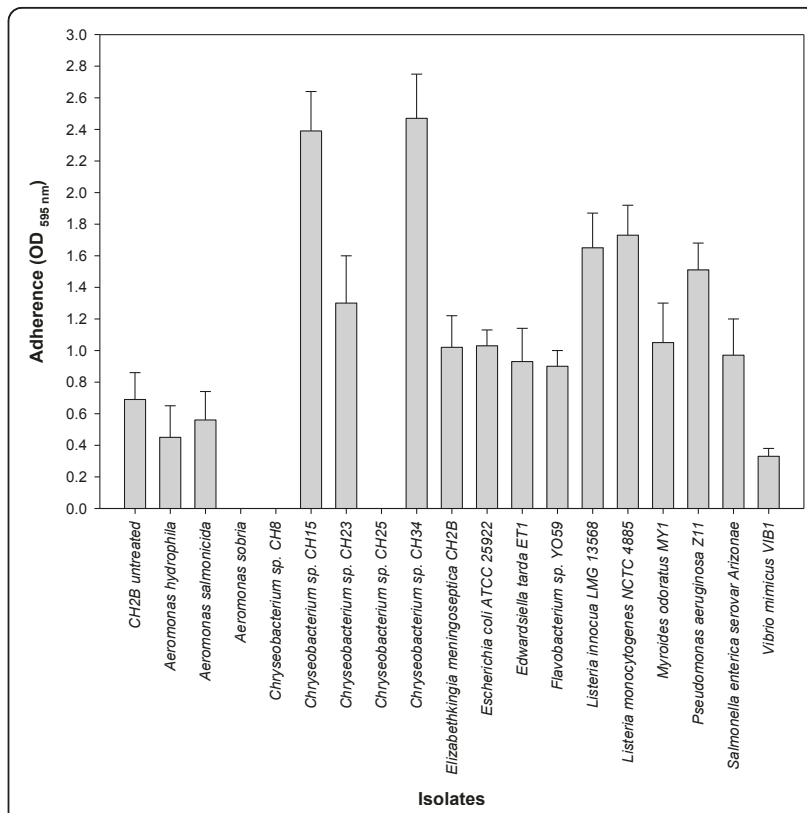

Figure 1 Microtiter plate adherence of E. meningoseptica isolate $\mathrm{CH} 2 \mathrm{~B}$, following exposure to cell-free spent medium supernatants from selected Gram-negative and Gram-positive bacteria, at room temperature $\left(21^{\circ} \mathrm{C} \pm 2^{\circ} \mathrm{C}\right)$ under static conditions in nutrient-rich (TSB) medium. Bars represent means \pm standard deviations for three independent replicate experiments.

thick, complex biofilm structure across entire channel surface (Figure $3 b$ ).

Distinction between bacterial strains in mixed-culture experiments was made visually by comparing images to that of pure culture, single-species flow cell experiments. Cells differed morphologically with E. meningoseptica

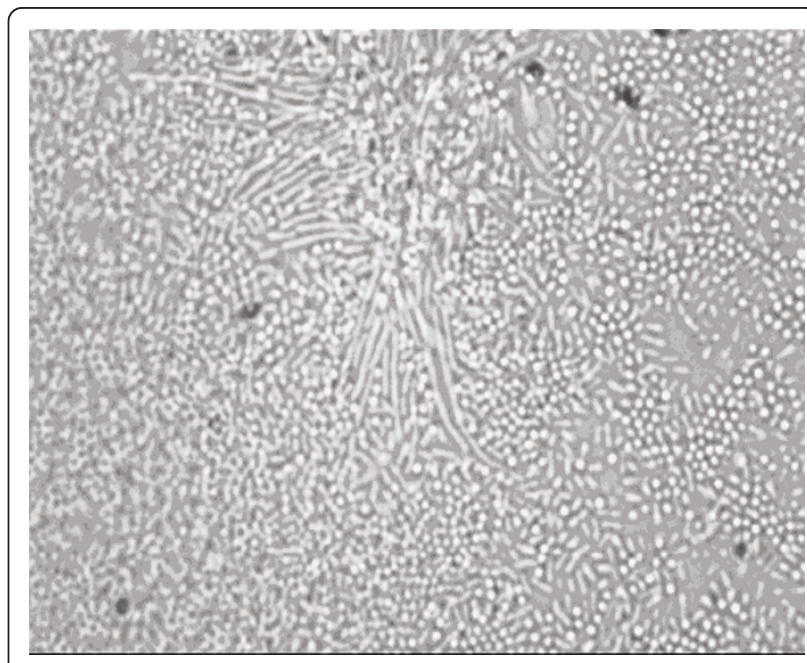

Figure 2 Light microscope image depicting polar attachment (arrow) of Elizabethkingia meningoseptica isolate CH2B biofilm cells to glass slide surface following $48 \mathrm{~h}$ of incubation in nutrient-poor (EAOB) medium ( $\times 1000$ magnification) 


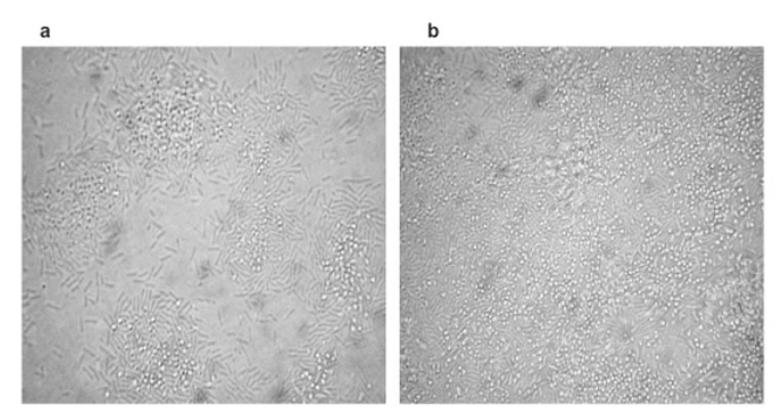

Figure 3 Light microscope images depicting Elizabethkingia meningoseptica isolate $\mathrm{CH} 2 \mathrm{~B}$ cells associated with the glass slide surface as a) microcolonies after $24 \mathrm{~h}$ and b) complex biofilm formation following $48 \mathrm{~h}$ of incubation in nutrient-rich (TSB) medium, respectively ( $\times 1000$ magnification).

CH2B cells being longer, thinner cells, and Listeria spp. shorter and thicker. When co-inoculated in nutrientpoor medium, both isolate $\mathrm{CH} 2 \mathrm{~B}$ and $L$. monocytogenes NCTC 4885 cells displayed delayed attachment to the glass surfaces, and attached cells were only observed 48 $\mathrm{h}$ following inoculation. Although both $\mathrm{CH} 2 \mathrm{~B}$ and $L$. monocytogenes NCTC 4885 cells were able to attach to the glass slides, distinct colonies were formed with no association between the different species (Figure 4). In nutrient-rich medium, cells of both species appeared to be scattered over the surface after $24 \mathrm{~h}$, but by $48 \mathrm{~h}$ only a monolayer of isolate $\mathrm{CH} 2 \mathrm{~B}$ was observed covering the surface of the glass slide.

\section{Discussion}

E. meningoseptica has been identified in infection outbreak associated with municipal water reservoirs,

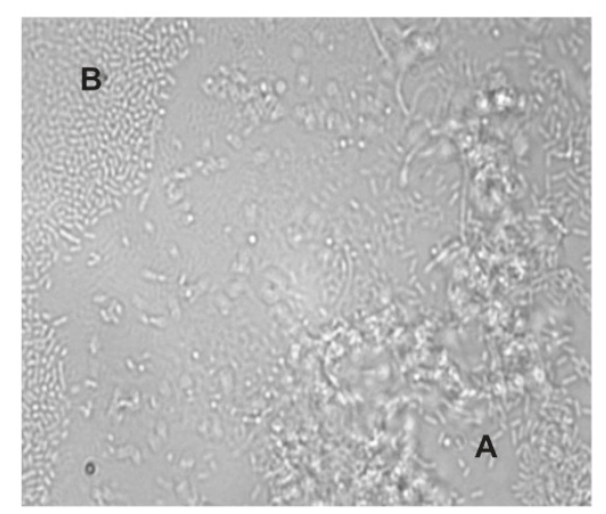

Figure 4 Light microscope image depicting the distinctly separate adherence of Elizabethkingia meningoseptica isolate CH2B microcolonies (A) and Listeria monocytogenes NCTC 4885 cells (B) following $48 \mathrm{~h}$ in flow cells containing nutrient-poor (EAOB) medium ( $\times 1000$ magnification). potable water [7] and colonization of tap water in a neonatal intensive care unit [7]. Infections associated with E. meningoseptica have been associated with instrumentation contamination or the internal placement of indwelling medical devices [5,20]. Although its role in infection appears to be linked to biofilm formation and a worse outcome in patients [5], no studies have focused on investigating the factors involved in the adherence of E. meningoseptica to abiotic or biotic surfaces.

The presence of E. meningoseptica in various hospital environments involves optimal growth conditions including moist, cool environments or standing water at approximately $21^{\circ} \mathrm{C}$ [8]. Typically a shift to oligotrophic conditions triggers adhesion and biofilm formation [21], however, the converse was observed for E. meningoseptica CH2B. Unlike $V$. mimicus isolate VIB1, biofilm formation for E. meningoseptica was optimal in nutrientrich TSB at both $21^{\circ} \mathrm{C}$ and $37^{\circ} \mathrm{C}$, respectively. Lin et al. [5] also observed strong E. meningoseptica isolate-specific biofilm formation in the relatively nutrient-rich Luria-Bertani medium. A similar trend was observed for Hafnia alvei, where higher nutrient concentrations favoured biofilm formation [22]. Myroides odoratus, a related organism, by contrast, displayed strong adherence in both nutrient-rich and poor media at $21^{\circ} \mathrm{C}$ but was moderately adherent at $37^{\circ} \mathrm{C}$ in nutrient-rich medium [23]. Biofilm formation by avian faecal commensal $E$. coli strains was induced by both nutrient-rich and nutrient-poor media [24]. Even under nutrient-poor conditions at both 21 and $37^{\circ} \mathrm{C}$, E. meningoseptica $\mathrm{CH} 2 \mathrm{~B}$ did not lose its ability to adhere, but displayed moderate biofilm-formation. Nutrient-poor conditions at lower temperatures and nutrient-rich medium at $37^{\circ} \mathrm{C}$ are conditions typically associated with environmental and clinical conditions, respectively. E. meningoseptica adherence occurred preferentially in nutrient-rich medium at both $21^{\circ} \mathrm{C}$ and $37^{\circ} \mathrm{C}$, suggesting that nutrient limitation is not a cue in the switch to a sessile lifestyle for E. meningoseptica. Altering the hydrodynamic conditions appeared to affect the degree of biofilm formation more significantly in nutrient-rich medium and requires further investigation.

Whole cell hydrophobicity, autoaggregation, and coaggregation are important for colonisation and biofilm development in flowing environments [25]. Bacteria behave as hydrophobic particles due to their net negative surface charge and this surface hydrophobicity is usually associated with bacterial adhesiveness, varying from organism to organism, from strain to strain and is influenced by the growth medium, bacterial age and bacterial surface structures $[26,27]$. Although the general rule has been that adhesiveness increases and decreases with increasing and decreasing hydrophobicity, respectively [28], a number of studies have shown contradictory 
results where no relationship was found between the bacterial strain's surface hydrophobicity and the extent of initial binding to either a hydrophilic or hydrophobic substrate [14,29]. Flavobacterium johnsoniae-like and F. psychrophilum isolates from fish were hydrophilic by the BATH assay [11,27], as were adhesion-defective mutants of a F. johnsoniae strain displaying poor adherence [26]. Although E. meningoseptica $\mathrm{CH} 2 \mathrm{~B}$ appeared to be very hydrophilic by both the BATH and SAT assays, it displayed strong adherence.

The hydrophilic nature of the E. meningoseptica isolates might account for cells adhering preferentially along the entire surface of the glass slide rather than to the perspex surfaces in flow cells. Majority of the cells attached by their polar sides to glass in nutrient-poor medium, which could be an attempt to increase surface area for nutrient uptake in nutrient-limited environments, since horizontal attachment was observed in nutrient-rich medium.

According to Ofek and Doyle [20], capsule presence obscures cell hydrophobicity. Coagulase-negative Staphylococcus strains with capsules were more hydrophilic than non-encapsulated strains [30,31]. E. meningoseptica CH2B's hydrophilicity might be explained in part by the presence of a capsule layer (unpublished data). The capsule presence might also account for the autoaggregation index of 37\%. Autoaggregation is a 'selfish' mechanism whereby a strain within the biofilm will express polymers to enhance the integration of genetically identical strains into biofilms [32], especially in high shear environments [25]. The high autoaggregation index could thus explain the aggregation of E. meningoseptica $\mathrm{CH} 2 \mathrm{~B}$ cells in the high shear inflow point of the flow-cell chambers.

Bacterial coaggregation is defined as cell-to-cell adherence of different bacterial species or strains [33]. Coaggregation plays an important role in the development of multi-species biofilms into integrated biological structures, by mediating the juxtaposition of species next to favourable partner species within taxonomically diverse biofilms [34]. The coaggregation profiles of isolate $\mathrm{CH} 2 \mathrm{~B}$ and strain NCTC $10016^{\mathrm{T}}$ were not identical and this might be accounted for in part by the environmental and clinical isolation sources of the respective bacteria and diverse selection pressures potentially experienced in their diverse ecological niches. The strongest coaggregation partners with Elizabethkingia spp. isolate $\mathrm{CH} 2 \mathrm{~B}$ were not other Gram-negative bacteria commonly found in the aquatic environment, i.e., Aeromonas or Flavobacterium spp., but rather organisms important in food spoilage and/or intoxications, i. e., S. aureus, L. innocua, L. monocytogenes, S. enterica, E. faecalis, and P. aeruginosa. A similar trend was observed for F. johnsoniae-like isolates [11]. M. luteus, B. natatoria, Fusobacterium and Prevotella spp. have been identified as bridging organisms in biofilms due to their ability to coaggregate with diverse coaggregating partners $[18,35,36]$. In the present study, study isolate $\mathrm{CH} 2 \mathrm{~B}$ displayed high coaggregation indices with 12 of the 19 partner strains, and it is, therefore, not unlikely that it is a possible bridging organism in aquaculture environments.

Although both $\mathrm{CH} 2 \mathrm{~B}$ and L. monocytogenes NCTC 4885 attached to the glass slide in the mixed-species flow cell experiment, the high coaggregation index displayed by these two bacterial species was not apparent. The microcolonies of the two species appeared to be distinctly separated from one another on the glass surface. Based on induction experiment data, extracellular molecules in Listeria spp. growth medium supernatants, as well as that of Chryseobacterium sp. isolates $\mathrm{CH} 15$ and $\mathrm{CH} 34$, and $P$. aeruginosa increased the adherence of E. meningoseptica isolate $\mathrm{CH} 2 \mathrm{~B}$ to microtiter plate surfaces more than 2-fold. Quorum sensing signaling molecules within the cell-free supernatants could account for the increased adherence to polystyrene microtiter plates. This might also explain the high coaggregation indices observed with Listeria sp. isolates and the increased, albeit separate, adherence observed for both L. monocytogenes and E. meningoseptica $\mathrm{CH} 2 \mathrm{~B}$ in the mixed-species biofilm flow cell experiments. The $37.4 \%$ autoaggregation index, and the increased adherence observed for isolate $\mathrm{CH} 2 \mathrm{~B}$ following exposure to its own cell-free supernatant, suggests a potential role for quorum sensing in autoaggregation and biofilm formation.

Cell surface components or properties (flagella, pili, adhesin proteins, capsules, and surface charge) influence attachment and coaggregation. Flagella facilitate bacterial motility to specific attachment sites, while changes in cellular physiology affects surface membrane chemistry, surface proteins such as pili and adhesins, synthesis of polysaccharides, and cell aggregation, all of which influence adhesion [37]. Adhesive bacteria have developed various strategies to scaffold or present their adhesins. These include surface appendages and structures that bear adhesins, i.e., flagella, fimbriae, capsules, outer membranes, loosely attached peripheral components, etc. Adhesins may be proteins, polysaccharides, lipids, or teichoic acids [30]. The coaggregation interaction is a highly specific process mediated by the recognition of either complementary lectin (sugar-binding proteins)carbohydrate molecules between the aggregating partners [33]; polysaccharides of capsule or LPS bind to lectins on host-cell surface; protein-protein; hydrophobic moieties of proteins on one cell binding with lipids on another cell; and/or lipid-lipid interactions. Receptors may contain carbohydrate or amino acid residues [30]. 
In order to investigate the type of adhesin structures present on the E. meningoseptica $\mathrm{CH} 2 \mathrm{~B}$ surface, inhibition of coaggregation assays were undertaken. Autoaggregation of $\mathrm{CH} 2 \mathrm{~B}$ cells was inhibited when untreated cells were paired with heat- or protease-treated cells. A similar trend was observed for Acinetobacter calcoaceticus [35]. Proteinase K treatment inhibited biofilm formation by non-typeable Haemophilus influenzae, as well as rapidly detached preformed biofilms [38]. Since both heat and protease treatments of E. meningoseptica $\mathrm{CH} 2 \mathrm{~B}$ resulted in decreased autoaggregation and coaggregation, heat- and protease-sensitive adhesins (lectins) appear to be localized on the E. meningoseptica cell surface. Attachment of heat- and protease-treated $E$. meningoseptica cells to untreated $L$. innocua and $L$. monocytogenes appears to involve different combinations of receptors, since variations were observed in the decreased coaggregation indices (Table 3). Heat- and protease-treatment of Listeria spp. cells resulted in increased coaggregation indices with untreated $\mathrm{CH} 2 \mathrm{~B}$ cells, indicating the presence of heat- and proteasestable listerial receptor molecules.

Sugar treatment did not produce a partial or complete inhibition of E. meningoseptica autoaggregation and coaggregation as observed for freshwater/aquatic bacteria $[17,35,36]$ and sewage sludge bacteria [16]. Since the lectin-saccharide interactions are usually very specific, a wider variety of sugars might have to be assayed to yield a reversal of the coaggregation reactions. However, protein-carbohydrate interactions were not reversed by sugars [16]. The increased autoaggregation and coaggregation indices with both lactose and galactose were unexpected. This occurred when either isolate $\mathrm{CH} 2 \mathrm{~B}$ or the listerial cultures were treated with sugars. It might be speculated that the treatment sugars added to the capsular material enclosing isolate $\mathrm{CH} 2 \mathrm{~B}$ and intensified the adhesive effect and thus coaggregation. While capsule presence may mask potential adhesins such as fimbriae, it may stabilize the adhesion-receptor interaction. The capsule chemical composition, while primarily polysaccharide may also include protein adhesion molecules. Thus the capsule components may also be receptors for lectins on another bacterium [30]. Thus, in addition to conferring a hydrophilic nature to the cell, the capsule in E. meningoseptica $\mathrm{CH} 2 \mathrm{~B}$ might play an integral role in the strong adherence ability of this organism.

Factors affecting coaggregation include: adhesin and receptor density and distribution; hydrophobic character of receptor, adhesin or receptor nearest neighbours; medium composition and $\mathrm{pH}$; and chelating agents [30]. Coaggregation among aquatic bacteria is mediated by lectin-saccharide interactions, and these aquatic strains often carry multiple adhesins or receptors or a combination of both, which is also a common feature of coaggregating oral bacteria [36]. Multiple adhesins may also be distributed around the E. meningoseptica cell surface allowing interactions with diverse microorganisms and colonization of diverse substrata. This would allow E. meningoseptica to compete successfully in a microorganism-rich environment.

The present study has shown that an E. meningoseptica isolate $\mathrm{CH} 2 \mathrm{~B}$ from tilapia possesses the ability to adhere to abiotic surfaces and form biofilms under various environmental conditions. Hydrodynamic flow in clinical or environmental niches may be more rapid than the rate of multiplication and unattached organisms will be eliminated, thus adhesion confers the important ability to colonise substrata [30]. E. meningoseptica $\mathrm{CH} 2 \mathrm{~B}$ was able to coaggregate with bacterial species important from a food and health perspective. Although E. meningoseptica are mostly described as opportunistic pathogens in both veterinary and human infections, the cause for concern arises from their association with pathogens and spoilage organisms causing great economic losses in the aquaculture and food industries and lethal device- or equipment-associated infections in immuno-compromised humans.

The ability of Elizabethkingia spp. to adhere to biotic and abiotic surfaces and the association with disease requires further study. Quantitative characterization and chemical analysis of the capsular material might provide valuable information regarding the capsule's role in the adherence abilities of E. meningoseptica. Furthermore, an investigation of specific cell-surface molecules mediating strong coaggregation abilities between $E$. meningoseptica and coaggregating partners may provide valuable information for anti-adhesion therapy which could be applied in aquaculture systems for the eradication of biofilms harbouring pathogenic organisms. The enhanced adherence of E. meningoseptica $\mathrm{CH} 2 \mathrm{~B}$ induced by cell-free supernatants points to the presence of a quorum sensing system, whose activity might be associated with autoaggregation, biofilm formation and/or the ability to colonise surfaces and initiate infection.

\section{Acknowledgements}

This work was funded b a Women in Science - Thuthuka Program grant to H.Y.C from the National Research Foundation of South Africa (TTK2003032000142).

\section{Author details}

'Department of Microbiology, University of Stellenbosch, Private Bag X1, Matieland, 7602, South Africa. ²Discipline: Microbiology, University of KwaZulu-Natal, Private Bag X54001, Durban, 4001, South Africa.

\section{Authors' contributions}

AJ participated in designing the experiments, executing them, and performing data analysis. HYC conceived the study, participated in its design, data analysis and coordination and drafted the manuscript. All authors read and approved the final manuscript. 


\section{Competing interests}

The authors declare that they have no competing interests.

Received: 13 January 2011 Accepted: 5 May 2011 Published: 5 May 2011

\section{References}

1. Bernardet J-F, Hugo C, Bruun B: The genera Chryseobacterium and Elizabethkingia. In The Prokaryotes. Volume 7.. 3 edition. Edited by: Dworkin M, Falkow S, Rosenberg E, Schleifer K-H, Stackebrandt E. New York: Springer; 2006:638-676.

2. Green O'N, Murray P, Gea-Banacloche JC: Sepsis caused by Elizabethkingia miricola successfully treated with tigecycline and levofloxacin. Diag Microbiol Infect Dis 2008, 62:430-432.

3. Lee C-H, Lin W-C, Chia J-H, Su L-H, Chien C-C, Mao A-H, Liu J-W: Community-acquired osteomyelitis caused by Chryseobacterium meningosepticum: case report and literature review. Diagn Microbiol Infect Dis 2008, 60:89-93.

4. Michel C, Matte-Tailliez O, Kerouault B, Bernardet J-F: Resistance pattern and assessment of phenicol agents' minimum inhibitory concentration in multiple drug resistant Chryseobacterium isolates from fish and aquatic habitats. J Appl Microbiol 2005, 99:323-332.

5. Lin P-Y, Chen H-L, Huang C-T, Su L-H, Chiu C-H: Biofilm production, use of indwelling catheters and inappropriate antimicrobial therapy as predictors of fatality in Chryseobacterium meningosepticum bacteraemia. Int J Antimicrob Agent 2010, 36:436-440.

6. Ceyhan M, Yildırım I, Tekelı A, Yurdakok M, Us E, Altun B, Kutluk T, Cengiz AB, Gurbuz V, Barın C, Bagdat A, Cetınkaya D, Gur D, Tuncel O: A Chryseobacterium meningosepticum outbreak observed in 3 clusters involving both neonatal and non-neonatal pediatric patients. Am J Infect Control 2008, 36:453-457.

7. Hoque SN, Graham J, Kaufmann ME, Tabaqchali S: Chryseobacterium (Flavobacterium. meningosepticum outbreak associated with colonization of water taps in a neonatal intensive care unit. J Hosp Infect 2001, 47:188-192.

8. Bloch KC, Nadarajah R, Jacobs R: Chryseobacterium meningosepticum: an emerging pathogen among immunocompromised adults: report of 6 cases and literature review. Med (Baltimore) 1997, 76:30-41.

9. Flemming L, Rawlings DE, Chenia HY: Phenotypic and molecular characterisation of fish-borne Flavobacterium johnsoniae-like isolates from aquaculture systems in South Africa. Res Microbiol 2007, 158:18-30.

10. Bernardet J-F, Kerouault B: Phenotypic and genomic studies of "Cytophaga psychrophila" isolated from diseased rainbow trout (Oncorhynchus mykiss) in France. Appl Environ Microbiol 1989, 55:1796-1800.

11. Basson A, Flemming LA, Chenia HY: Evaluation of adherence, hydrophobicity, aggregation characteristics and biofilm development of Flavobacterium johnsoniae-like isolates from South African aquaculture systems. Microb Ecol 2008, 55:1-14.

12. Stepanović S, Vuković D, Davić I, Savić B, Švabić-Vlahović M: A modified microtiter-plate test for quantification of staphylococcal biofilm formation. J Microbiol Method 2000, 40:175-179.

13. Rosenberg M, Gutnick D, Rosenberg E: Adherence of bacteria to hydrocarbons: a simple method for measuring cell-surface hydrophobicity. FEMS Microbiol Lett 1980, 9:29-33.

14. Mattos-Guaraldi AL, Formiga LCD, Andrade AFB: Cell surface hydrophobicity of sucrose fermenting and nonfermenting Corynebacterium diphtheriae strains evaluated by different methods. Curr Microbiol 1999, 38:37-42.

15. Møller JD, Larsen JL, Madsen L, Dalsgaard I: Involvement of a sialic acidbinding lectin with hemagglutination and hydrophobicity of Flavobacterium psychrophilum. Appl Environ Microbiol 2003, 69:5275-5280.

16. Malik A, Sakamoto M, Hanazaki S, Osawa M, Suzuki T, Tochigi M, Kakii K: Coaggregation among nonflocculating bacteria isolated from activated sludge. Appl Environ Microbiol 2003, 69:6056-6063.

17. Rickard AH, McBain AJ, Ledder RG, Handley PS, Gilbert P: Coaggregation between freshwater bacteria within biofilm and planktonic communities. FEMS Microbiol Lett 2003, 220:133-140.

18. Kolenbrander PE, Andersen RN, Holdeman LV: Coaggregation of oral Bacteroides species with other bacteria: central role in coaggregation bridges and competitions. Infect Immun 1985, 48:741-746.
19. Rickard AH, Gilbert P, Handley PS: Influence of growth environment on coaggregation between freshwater biofilm bacteria. J Appl Microbiol 2004, 96:1367-1373.

20. Kumar R, Stephens JL: Septic arthritis caused by Chryseobacterium meningosepticum in an elbow joint prosthesis. South Med J 2004, 97:74-76.

21. Harvey J, Keenan KP, Gilmour A: Assessing biofilm formation by Listeria monocytogenes strains. Food Microbiol 2007, 24:380-392.

22. Vivas J, Padilla D, Real F, Bravo J, Grasso V, Acosta F: Influence of environmental conditions on biofilm formation by Hafnia alvei strains. Vet Microbiol 2008, 129:150-155.

23. Jacobs A, Chenia HY: Biofilm-forming capacity, surface hydrophobicity and aggregation characteristics of Myroides odoratus isolated from South African Oreochromis mossambicus fish. J Appl Microbiol 2009, 107:1957-1966.

24. Skyberg JA, Siek KE, Doetkott C, Nolan LK: Biofilm formation by avian Escherichia coli in relation to media, source and phylogeny. $J$ Appl Microbiol 2007, 102:548-554.

25. Rickard AH, McBain AJ, Stead AT, Gilbert P: Shear rate moderates community diversity in freshwater biofilms. Appl Environ Microbiol 2004, 70:7426-7435

26. Sorongon ML, Bloodgood RA, Burchard RP: Hydrophobicity adhesion and surface-exposed proteins of gliding bacteria. Appl Environ Microbiol 1991 57:3193-3199.

27. Vatsos IN, Thompson KD, Adams A: Adhesion of the pathogen Flavobacterium psychrophilum to unfertilized eggs of rainbow trout (Oncorhynchus mykiss) and n-hexadecane. Lett Appl Microbiol 2001, 33:178-182.

28. Van Loosdrecht MCM, Lyklema J, Norde W, Scraa G, Zehnder AJB: The role of bacterial cell wall hydrophobicity in adhesion. Appl Environ Microbiol 1987, 53:1893-1897.

29. Coquet L, Cosette P, Junter G-A, Beucher E, Saiter J-M, Jouenne T: Adhesion of Yersinia ruckeri to fish farm materials: influence of cell and material surface properties. Colloids Surf B: Biointerfaces 2002, 26:373-378.

30. Ofek I, Doyle RJ: Bacterial adhesion to animal cells and tissues Washington, D.C.: ASM Press; 1994.

31. Hogt AH, Dankert J, Feien J: Encapsulation, slime production and surface hydrophobicity of coagulase-negative staphylococci. FEMS Microbiol Lett 1983, 18:211-215.

32. Rickard AH, Gilbert P, High NJ, Kolenbrander PE, Handley PS: Bacterial coaggregation: an integral process in the development of multi-species biofilms. Trends Microbiol 2003, 11:94-100.

33. Shen S, Samaranayake LP, Yip H-K: Coaggregation profiles of the microflora from root surface caries lesions. Arch Oral Biol 2005, 50:23-32.

34. Kolenbrander PE: Oral microbial communities: biofilms interactions and genetic systems. Annu Rev Microbiol 2000, 54:413-437.

35. Simoes LC, Simoes M, Viera MJ: Intergeneric coaggregation among drinking water bacteria: evidence of a role for Acinetobacter calcoaceticus as a bridging bacterium. Appl Environ Microbiol 2008, 74:1259-1263

36. Rickard AH, Leach SA, Buswell CM, High NJ, Handley PS: Coaggregation between aquatic bacteria is mediated by specific-growth-phasedependent lectin-saccharide interactions. Appl Environ Microbiol 2000, 66:431-434.

37. Chmielewski RAN, Frank JF: Biofilm formation and control in food processing facilities. Compr Rev Food Sci Food Saf 2003, 2:22-32.

38. Izano EA, Shah SM, Kaplan JB: Intercellular adhesion and biocide resistance in nontypeable Haemophilus influenzae biofilms. Microb Pathog 2009, 46:207-213.

\section{doi:10.1186/1476-0711-10-16}

Cite this article as: Jacobs and Chenia: Biofilm formation and adherence characteristics of an Elizabethkingia meningoseptica isolate from Oreochromis mossambicus. Annals of Clinical Microbiology and Antimicrobials 2011 10:16. 